\title{
Uncertainties in future air quality: a scientific workflow tool
}

\author{
$\underline{\text { L. Gidhagen }}^{\text {a }}$, M. Engardt ${ }^{\text {a }}$, S. Schlobinski ${ }^{\text {b }}$, R. Denzer ${ }^{\text {c }}$ and P. Kutschera ${ }^{\text {d }}$ \\ ${ }^{a}$ Swedish Meteorological and Hydrological Institute, Norrköping, Sweden \\ Email: lars.gidhagen@smhi.se \\ ${ }^{b}$ cismet GmbH, Saarbrücken, Germany \\ ${ }^{c}$ Environmental Informatics Group, Saarbrücken, Germany \\ ${ }^{d}$ Austrian Institute of Technology, Vienna, Austria
}

\begin{abstract}
Future air quality in large cities will not only depend on how sustainable the city administration will be in terms of how they introduce clean technologies and organize the energy, heating and transport systems. Urban air quality will also be affected by global, hemispheric and regional contributions of longrange transported pollutants, for which the future evolution is depending on international emission protocols and undertakings. An additional factor is climate change, which will modify the atmospheric response to a certain trace gas emission scenario. All these factors - local urban emissions, long range regional contributions to air pollution and finally the climate change effect - should be considered in long term urban planning, so that appropriate actions can be taken to avoid negative health impacts due to air pollution exposure.
\end{abstract}

The FP7 project SUDPLAN (www.sudplan.eu) facilitates a platform for assessing the importance of all the factors mentioned above, separately and all together. This allows quantitative assessments in a particular European city - e.g. in Stockholm, the example given here - of how much climate change affects future air pollution levels, how much the EU undertakings in terms of emission reductions will contribute to long range transported pollutants and how much the city itself can influence future air pollution by mitigating local emissions. Future emissions and climate are uncertain, thus they are given as possible scenarios. By comparing different scenario simulations, based on different global climate models and different scenarios for how European emissions will evolve, an indication is given of how "robust" an individual model result is (the ensemble approach). Another uncertainty originates from the assumptions made while preparing the city's future emission inventory, used as input data to the model. This latter uncertainty can be assessed separately from the climate and European emission uncertainties.

The SUDPLAN tool includes distributed services both for accessing scenarios of global/regional climate and environmental information and - with use of those at the boundaries - for executing downscaling simulations of intense rainfall (stormwater flooding), hydrological conditions (river discharge, soil moisture) and urban air quality. The present paper describes an application of SUDPLAN to assess air quality in Stockholm, how future ozone and nitrogen dioxide levels will be affected by climate change and varying European trace gas emissions.

For ozone, which is a secondary pollutant generated by precursors emitted outside Stockholm city centre, there is a rather clear trend that air coming into Stockholm will have a lower ozone level in the future. The simulation is based on the assumption that Europe can follow the emission reductions required for achieving no more than a $4.5 \mathrm{Wm}^{-2}$ radiative forcing at year 2100. The SUDPLAN downscaling of ozone shows that up to $\sim 2030$ average ozone levels in the Stockholm center will be reduced by about $5 \mu \mathrm{gm}^{-3}(\sim 10 \%)$. The rather large inter-annual variability will however permit high extreme values to occur also in the future.

For $\mathrm{NO}_{2}$, which is to a high degree locally generated, there is no clear trend in long range transport levels. The dominating impact of local sources makes the effect of long-range transport and climate change of little importance, so that local actions on $\mathrm{NO}_{\mathrm{x}}$ emissions will be decisive for accomplishing reduced $\mathrm{NO}_{2}$ levels. Measured inter-annual differences in measured $\mathrm{NO}_{2}$ levels, larger than the differences found between simulated present and 2030 levels, point towards the importance of meteorological variability.

Keywords: Decision Support System (DSS), air quality, climate scenarios, urban planning. 


\section{INTRODUCTION}

Stockholm is one of the Swedish cities that do not meet EU standards for nitrogen dioxide $\left(\mathrm{NO}_{2}\right)$ and suspended particles smaller than $10 \mu \mathrm{m}\left(\mathrm{PM}_{10}\right)$. Stockholm municipality is developing an action plan principally appointing road traffic - to reduce air pollution levels, but there are concerns that climate change may bring about effects on air quality that will require special attention and other actions than those prioritized today. The Stockholm development plan "Vision 2030", developed in collaboration with regional public sectors as e.g. road traffic administration, foresee a population growth of 150000 inhabitants up to year 2030 and the objective is that the city shall be fossil free by the year 2050 .

Stockholm participates in the FP7 project SUDPLAN (ㅁustainable Urban ㅁevelopment Planner for Climate Change Adaptation) as a pilot city and through the Stockholm-Uppsala Air Quality Association (SULVF). SULVF is a non-governmental organization consisting of all municipalities in the region together with other public administrations and private companies that contributes to air pollution. SULVF takes over from the municipalities the control of air pollution with respect to compliance with limit values, emissions and exposure. The association is technically supported, e.g. in terms of monitoring and modeling work (including the operation of the SUDPLAN tool), by SLB, a department for air quality control and impact assessment of Stockholm municipality.

Road traffic constitutes a dominating emission source in Stockholm. The future development of road traffic is thus a local factor with significant importance for future air quality in Stockholm. A highly relevant example is the planning of a new north-south transit road system, for which different alternatives are under consideration (Figure 1).

The new transit road system is an example of a large urban infrastructure project that will affect the air quality in Stockholm. A relevant way to explore how local factors may influence future air quality is to assess the air quality given by "no project" (i.e. today's road system but with future traffic demand and vehicle technologies) and compare it with the impact as given by one or two of the proposed transit road scenarios.

The exposure to air pollution in Stockholm is however only partially determined by local emissions. Long range transported pollutants arise from emissions both in other parts of Sweden as well as in the rest of Europe. How the long range transported air pollution arriving to Stockholm will develop in the future is highly dependent on the economic growth and technology development in continental Europe. Also climate change itself will affect future air quality. Changes in temperature and precipitation will have direct effects on atmospheric chemistry and removal of air pollutants, but there are also indirect and highly complex effects e.g. through changes in vegetation patterns that affects deposition of pollutants and biogenic emissions. Our knowledge on future climate conditions comes principally from the results of global climate model simulations with coupled atmospheric and oceanic general circulation models (GCMs).

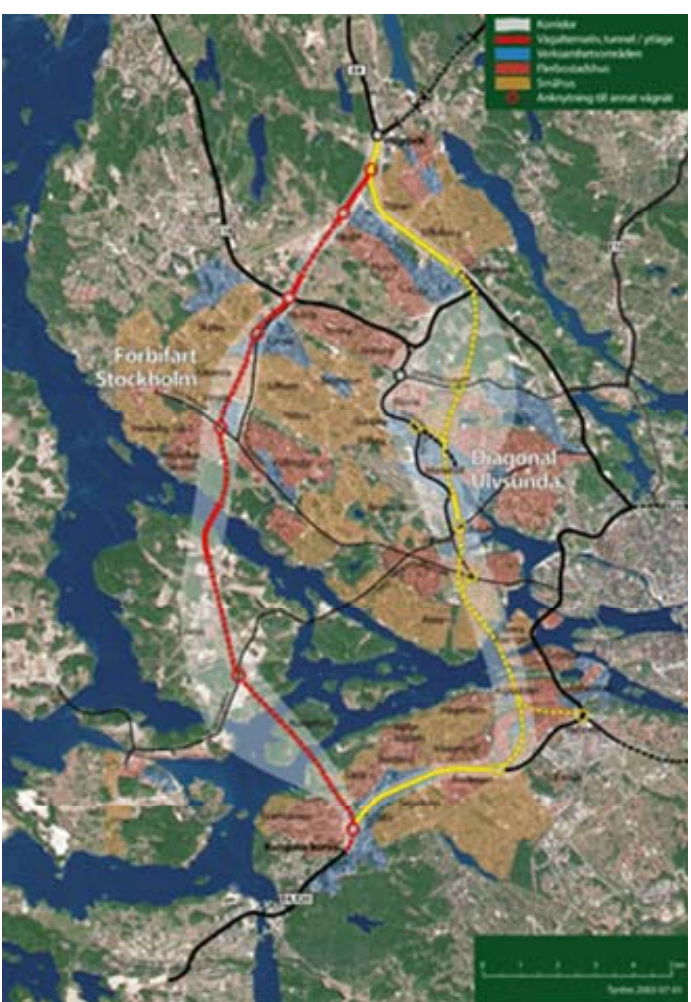

Figure 1. Western part of Stockholm with present major roads (continuos lines) and two planning alternatives for north-south transit (yellow and red broken lines).

The paper describes the software tool developed in

SUDPLAN (Gidhagen et al., 2010; Denzer et al., 2011) and how it can be used to assess future air quality in Stockholm, taking into account different evolutions of local emissions, European emissions and climate change. In particular we will discuss how different climate and emission scenarios for Europe will affect the urban background levels of nitrogen dioxide and ozone in Stockholm. 


\section{THE SUDPLAN PROJECT}

\subsection{Overview}

SUDPLAN is a project co-funded by the European Framework Program 7. The objective is to combine IT and environmental expertise to develop a highly interactive decision support system for facilitating environmental impact assessments in urban planning. IT partners contribute with state-of-the-art technologies for web based software and services, while the environmental partners contribute with environmental information and models. Figure 2 shows the two major software components, the Scenario Management System (SMS) and the Common Services (CS) with access to European scale environmental data and models for urban downscaling. The communication is based on standards wherever possible (for instance standards of the Open Geospatial Consortium), which means that the different services can be linked to specific city applications and to external software. SUDPLAN has four pilots that will demonstrate different aspects of the system. Stockholm is the main demonstrator of how SUDPLAN can be used for assessing future urban air quality.

There are always uncertainties involved in model simulations of future environmental conditions. Some of these uncertainties are due to our lack of knowledge of how nature works, something which is difficult to quantify. Other uncertainties are due to imperfections in numerical model description and in model input data. The latter type of uncertainty can to a certain extent be assessed through running comparable simulations with different models and model input. SUDPLAN Common Services uses this concept to achieve more robust conclusions on future air quality (often referred to as ensemble modeling).

Long range transport and climate change: SUDPLAN has access to pan-European model results of climate and air quality, based on multiple GCM output and trace gas emission scenarios in Europe. The Stockholm example discussed here used the results of two different GCMs, simulating the same greenhouse gas evolution from ICCPs $4^{\text {st }}$ Assessment Report (AR4). Some 3-4 different climate scenarios is expected to be available at project end, some likely from AR5. As for trace gas emission scenarios in Europe, two scenarios are discussed here below and a couple more scenarios are planned to be available in Common Services. Combining global climate and European emissions there will then be some 6-10 different scenarios ready to be used to assess the long range contribution of air pollution, for whatever city in Europe.

Local scenarios: As SUDPLAN is dynamically performing urban downscaling on request by the user, there are no limit on the number of local emission scenarios that can be used to assess possible future conditions. A typical large infrastructure project, like the one described in Stockholm, will likely generate at least 2-3 future emission scenarios to be evaluated in terms of air pollution impact.

\subsection{Air quality downscaling}

Figure 3 gives a functional overview of how the end-user can use the SMS to select area and boundary conditions for an air quality downscaling. The Scenario Database contains gridded climate and air quality data covering Europe, based on selected GCM results that have been further downscaled to the European scale (SMHI RCA model: Kjellström et al., 2011) and complemented with dispersion calculations (SMHI MATCH model: Robertson et al., 1999; Engardt et al., 2009) of the trace gases of interest while assessing air quality. 
Gidhagen et al., Uncertainties in future urban air quality: a scientific workflow tool

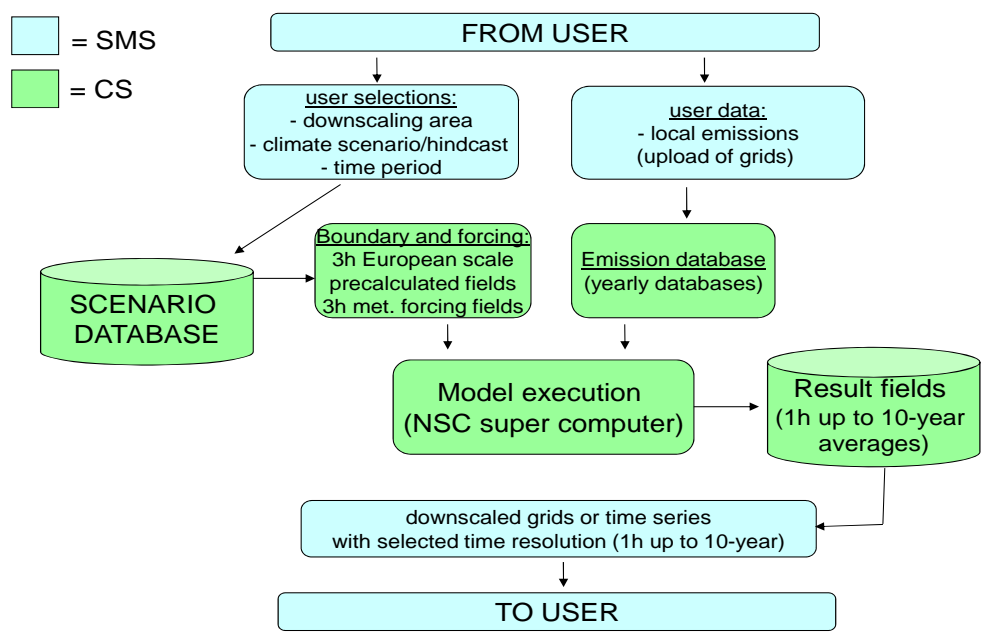

Figure 3. Work flows while performing an air quality downscaling (SMS = Scenario Management System, CS = Common Services)

\section{RESULTS}

\subsection{Long range contributions}

Before running the Stockholm downscaling, we will present and discuss the effect of different climate and European emission scenarios on future ozone levels. The results are those that will be used as forcing and boundary conditions for further urban downscaling, e.g. in Stockholm. The SUDPLAN tool allows the visualization and analysis of the pan-European information.

Table 1 summarizes the four scenarios analyzed in terms of tendencies for ozone levels on the European scale. In order to generalize the analysis, we evaluate annual average levels of ozone for six regions (Figure 4). Both the ECHAM5 A1B (Roeckner et al., 2006; Jungclaus et al., 2006) and the HADCM3 A1B (Gordon et al., 2000) model results were cited in the ICCP $4^{\text {th }}$ Assessment Report, the A1B representing an intermediate scenario. The RCP4.5 trace gas emissions comes from the more recent emission scenario (Representative Concentration Pathways, Moss et al., 2010), for which a global radiation forcing of $4.5 \mathrm{Wm}^{-2}$ is expected at year 2100 .
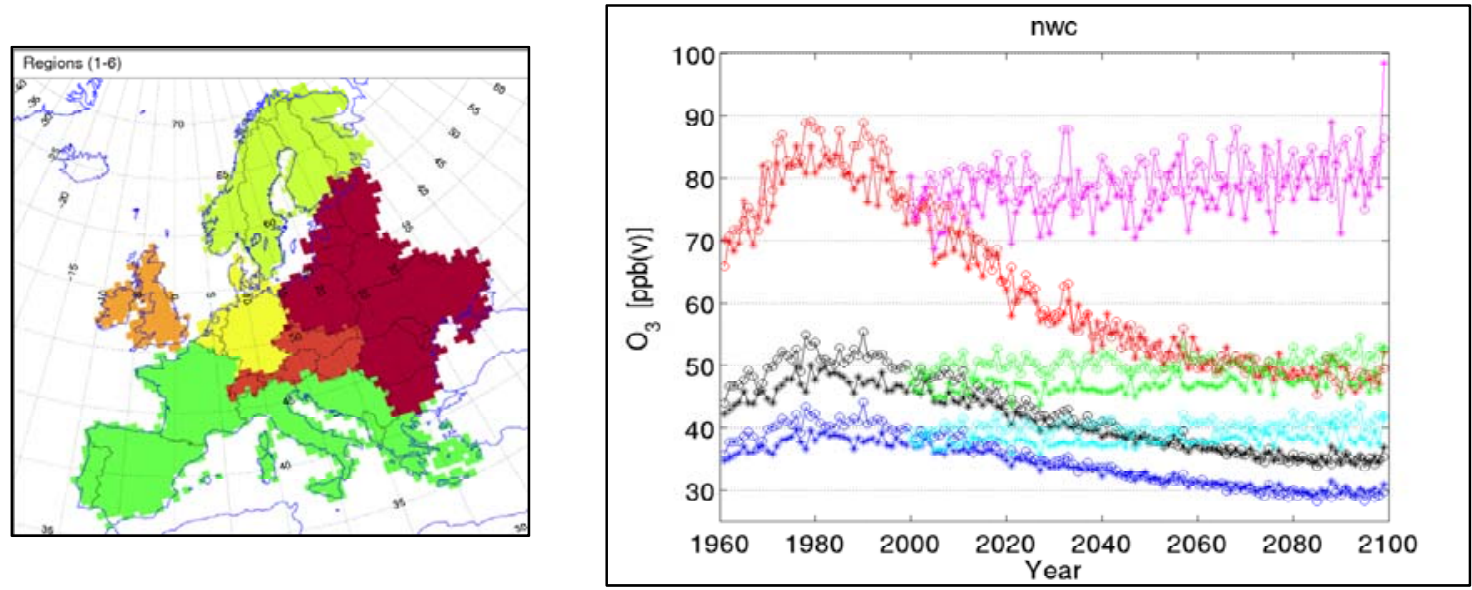

Figure 4. Regions used for analyzing the ozone response to different climate and emission scenarios (left) and time series plots of annual ozone data (right) as mean of daily maximum during summer six months (red), the same but after filtering with 8h running mean (black) and summer six month averages (blue) for the northern continental European region (yellow in left panel). Circles display the simulations based on the HADCM3 A1B climate scenario and crosses the ECHAM5 A1B scenarios. Time series starting year 2000 show the development of each scenario with European RCP4.5 emissions held constant at vear 2000 level. 
For the Northern Continental European region, taken as example here, both extreme values and annual averages show a clearly decreasing trend after 1990. However, with constant emissions in Europe after year 2000, the ozone decrease shifts to become more constant or to slowly increase. We can thus conclude:

- Future long range contributions of to urban air quality in Northern Continental Europe are likely to decrease, as long as Europe continues its reduction of ozone precursor emissions like nitrogen oxides and hydrocarbons.

- If emissions are not reduced, we can expect that climate change will contribute to slightly increased ozone levels in Northern Continental Europe.

\subsection{Downscaled air quality over Stockholm}

The two European scale scenarios, based on HADCM3 A1B and ECHAM5 A1B (with time varying emissions), have been used as forcing and boundary conditions to high resolution MATCH simulations with 2x2 km spatial resolution over Stockholm. The SUDPLAN project does not yet dispose future scenarios for local emissions of the type described in the introduction (representing different solutions for major road infrastructure projects). Therefore there will be only one Stockholm emission scenario representing current (year 2010) conditions. The air quality projections will thus give us the answer to what will happen with air quality if local emissions are kept unchanged.
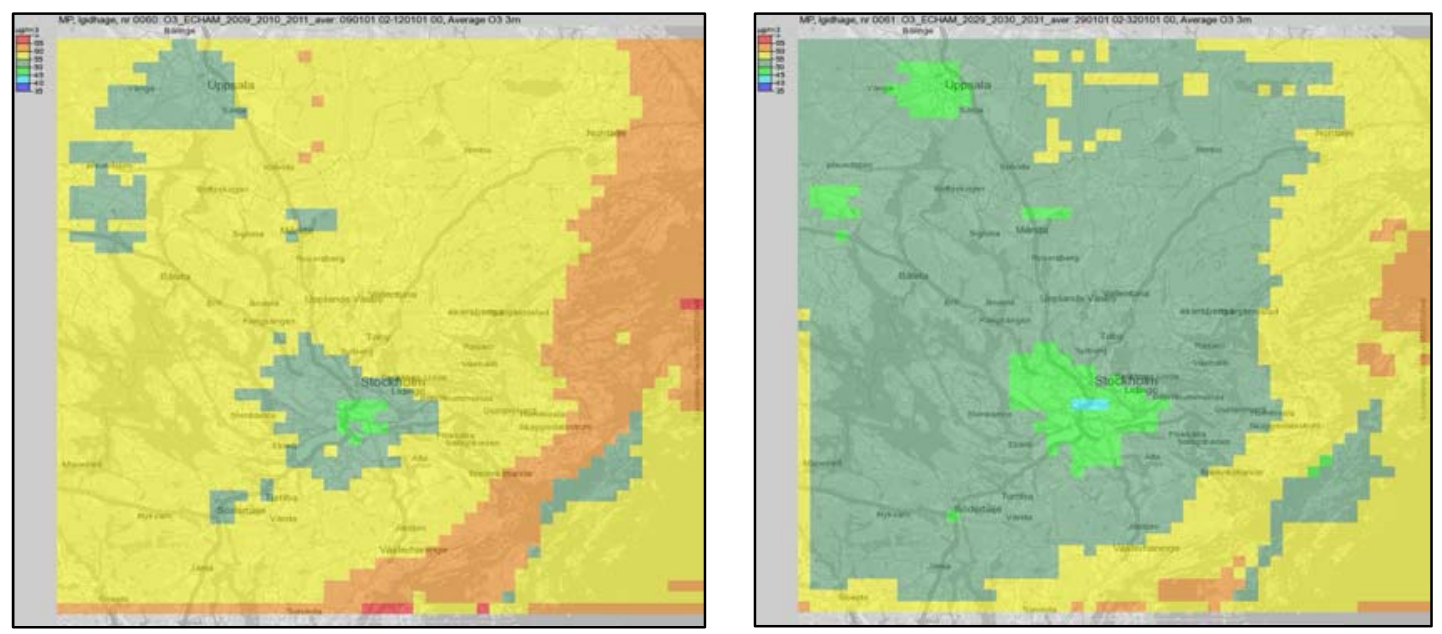

Figure 5. Average levels of urban background ozone concentrations: Year 2009-2011 (left) and year 2029-2031 (right) with ECHAM5 A1B climate scenario and RCP4.5 time varying emissions.

For ozone the highest values are found in the periphery of the city, especially over the Baltic Sea surface to the east (Figure 5). Central urban ozone levels are lower since locally emitted NO will consume ozone while oxidized to $\mathrm{NO}_{2}$. As the same emission inventory of 2010 is used both for the 2009-2011 and the 2029-2031 downscaling, total ozone will respond to changes in incoming long range transported air and the reduction is similar over the Stockholm area. The average ozone reduction is minor, about $5 \mu \mathrm{gm}^{-3}(\sim 10 \%)$ from year 2010 (Figure 5 left) to year 2030 (Figure 5 right).

In Figure 6 the modeled annual average and maximum 8-hour running mean values, are evaluated in the center of the city, at the monitoring station "Torkel Knutsson”. Measured values compare reasonably well to simulated levels, however a year-to-year similarity cannot be expected as the climate scenario meteorology does not reflect actual meteorological conditions for those two particular years.
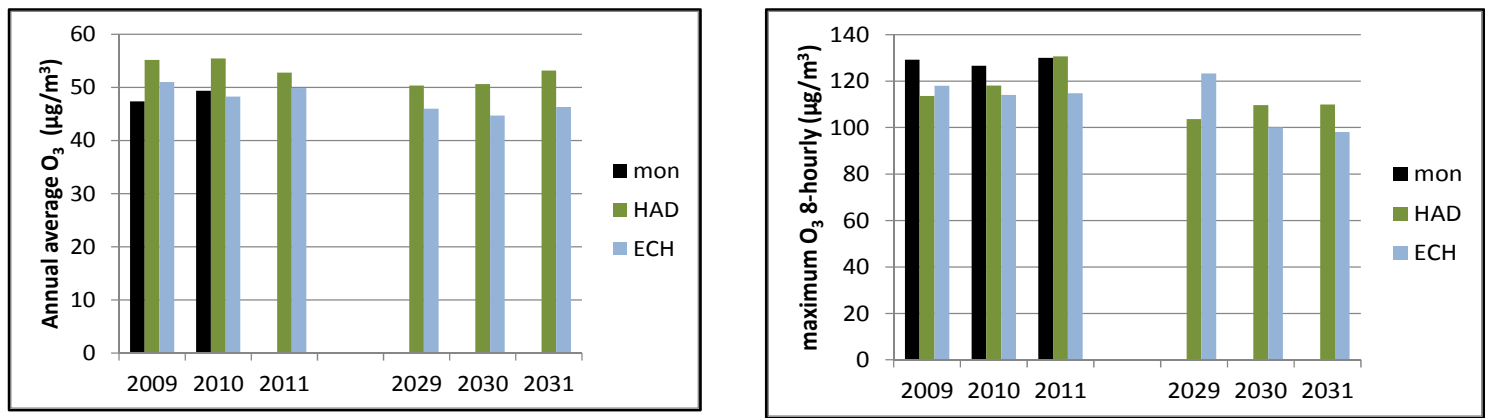

Figure 6. Urban background concentrations of ozone in the center of Stockholm (monitor stations "Torkel Knutsson”, located at roof level): Annual averages (left) and maximum 8-hour running mean values (right, with 2011 measured value based on summer period only). 
Although three-year averaged ozone levels show a smaller decreasing tendency, there is an important yearto-year variability. This is even most striking for extreme values, as the maximum 8-hour mean value labeled "2029" is higher than for any other year (HADCM3 based downscaling Figure 6, right diagram).

The corresponding comparisons for nitrogen dioxide are shown in Figure 7 and 8 . The expected reduction of $\mathrm{NO}_{2}$ in future long range transport is not sufficient to reduce city center concentrations. Variations from year to year seem larger than long term differences between 2009-2011 and 2029-2031. Measured concentrations from 2009 and 2010 indicate a large inter-annual variability compared to the differences in calculated $\mathrm{NO}_{2}$ concentrations.
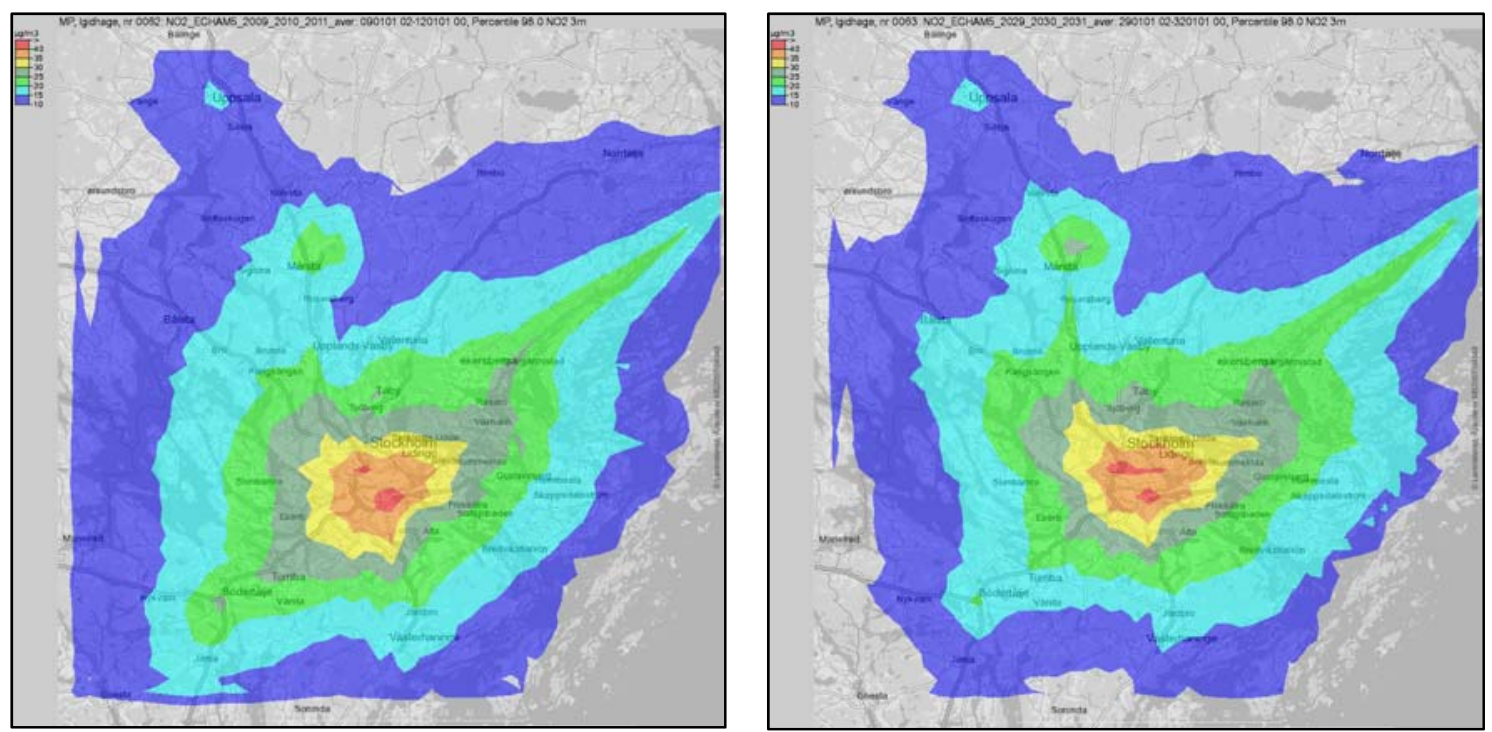

Figure 7. Extreme levels - 98-percentiles of hourly values - for urban background concentrations of nitrogen dioxide: Year 2009-2011 (left) and year 2029-2031 (right) with ECHAM5 A1B climate scenario and RCP4.5 time varying emissions.
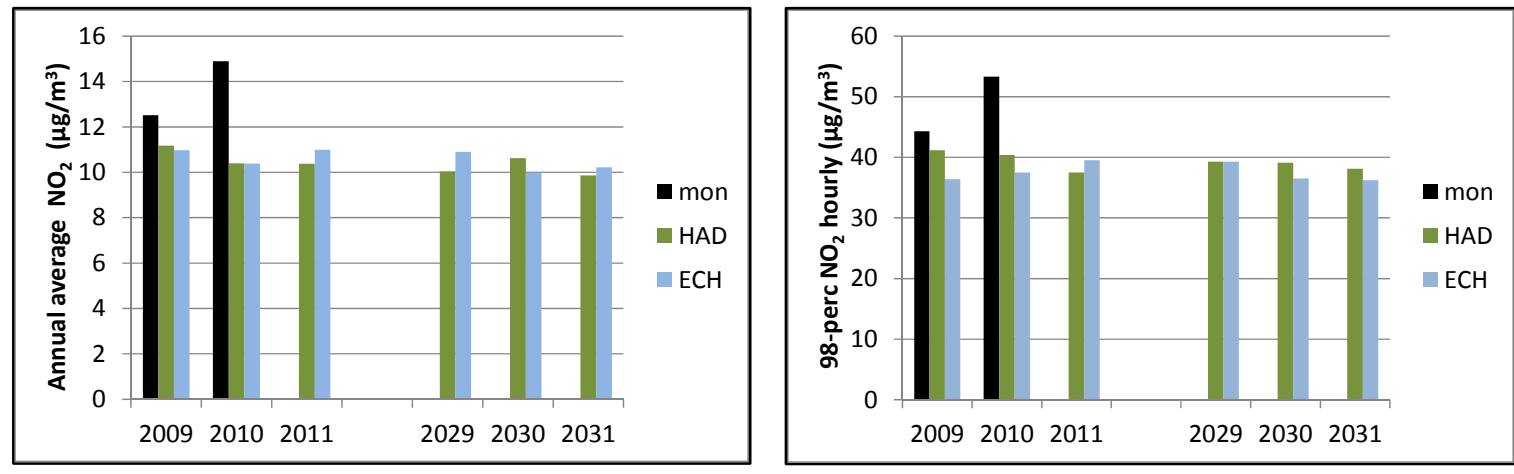

Figure 8. Urban background concentrations of nitrogen dioxide in the center of Stockholm (monitor stations “Torkel Knutsson”, located at roof level): Annual averages (left) and 98-percentiles of hourly values (right).

\section{DISCUSSION AND CONCLUSIONS}

We have used the SUDPLAN tool to assess how two air pollutants may develop in Stockholm up to about 2030. For ozone, which is a secondary pollutant generated by precursors emitted outside Stockholm, there is a rather clear trend that air coming into Stockholm will have a lower ozone concentration in the future. A prerequisite for this to happen is that Europe, as a region, can follow the planned emission reductions in order to reach no more than a $4.5 \mathrm{Wm}^{-2}$ radiative forcing by the year 2100 (RCP4.5 emission scenario). The SUDPLAN downscaling of ozone indicates that up to 2030 average ozone levels in the Stockholm center

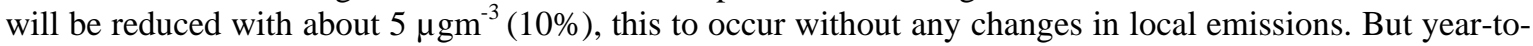
year variations will still be important and high extreme values may appear also in the future.

For $\mathrm{NO}_{2}$, which is to a high degree locally generated, there is no clear trend in long range transport levels. The dominating impact of local sources makes the effect of long-range transport and climate change of little 
importance, so that local actions on $\mathrm{NO}_{\mathrm{x}}$ emissions will be decisive for accomplishing reduced $\mathrm{NO}_{2}$ levels. Inter-annual differences in meteorology give a variability in simulated $\mathrm{NO}_{2}$ levels that is as large as the differences between present and 2030 conditions. Figure 8 also show measured inter-annual differences in $\mathrm{NO}_{2}$ levels, likely resulting from meteorological variability, that are larger than the differences found between simulated present and 2030 levels. Measured $\mathrm{NO}_{2}$ levels have shown a decreasing trend from

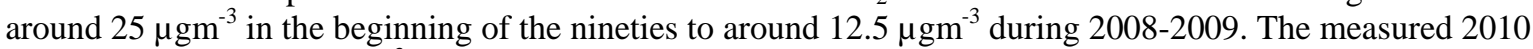
$\mathrm{NO}_{2}$ level close to $15 \mathrm{\mu gm}^{-3}$ is thus likely to represent an extreme year, caused by particular meteorological conditions that are not included in the three years of the climate scenarios HADCM3 and ECHAM5.

For urban planning in Stockholm the future levels of $\mathrm{NO}_{2}$ and $\mathrm{PM}_{10}$ are of most interest, to assure compliance with national standards. From the results presented in this paper, we can conclude that changes in the European emissions and in the climate will not solve the $\mathrm{NO}_{2}$ problem in Stockholm, this must be accomplished through local mitigation of $\mathrm{NO}_{\mathrm{x}}$ emissions. Within the coming year the SUDPLAN tool will be used to assess the local emission scenarios of primary interest. The assessment will also include PM $_{10}$ (not presented in this paper, as the emission inventories are still incomplete). Future work will also include downscaling simulations of more years, for a better determination of inter-annual variations.

While introducing air quality in urban planning, it should be noted that it is very difficult to drastically reduce air pollution levels over the urban scale. However, even minor reductions in exposure levels - perhaps only a

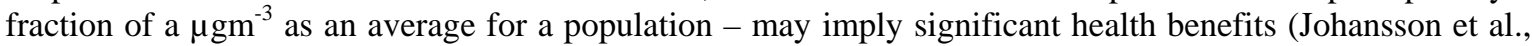
2009). A further analysis of the SUDPLAN air quality downscaling results together with population data will be used to include exposure and health impact assessments, thereby creating a basis for comparing health related economic cost or benefit scenarios in long term urban planning.

\section{ACKNOWLEDGMENTS}

SUDPLAN is a Collaborative Project (contract number 247708) co-funded by the Information Society and Media DG of the European Commission within the RTD activities of the Thematic Priority Information Society Technologies.

\section{REFERENCES}

Denzer, R., Schlobinski, S., Gidhagen, L. (2011). A Decision Support System for Urban Climate Change Adapatation. In: Proceedings of the 44th Hawaii International Conference on System Sciences.

Engardt, M., Bergström, R., Andersson, C. Climate and Emission Changes Contributing to Changes in Nearsurface Ozone in Europe over the Coming Decades: Results from Model Studies. (2009). Ambio, 38, 8, 452-458.

Gidhagen, L., Denzer, R., Schlobinski, S., Michel, F., Kutschera, P., Havlik, D. (2010). Sustainable Urban Development Planner for Climate Change Adaptation (SUDPLAN). In: Berre, A.; Roman, D.; Maué P., Proceedings of ENVIP'2010 workshop at EnviroInfo2010, "Environmental Information Systems and Services - Infrastructures and Platforms”, Bonn, October 6-8, 2010, CEUR-WS, Vol-679, ISSN 16130073, urn:nbn:de:0074-679-9.

Gordon, C., Cooper, C., Senior, C.A., Banks, H., Gregory, J.M. and co-authors. (2000). The simulation of SST, sea ice extents and ocean heat transports in a version of the Hadley Centre coupled model without flux adjustments. Clim. Dyn., 16.

Johansson, C., Burman, L., Forsberg, B. (2009). The effects of congestions tax on air quality and health. Atmospheric Environment, 43, 4843-4854.

Jungclaus, J.H., Botzet, M., Haak, H., Keenlyside, N., Luo, J.-J. and co-authors. (2006). Ocean cireculation and tropical variability in the coupled ECHAM5/MPI-OM. J. Clim., 19.

Kjellström, E., Nikulin, G., Hansson, U., Strandberg, G, Ullerstig, A. (2011). 21st century changes in the European climate: uncertainties derived from an ensemble of regional climate model simulations. Tellus, 63A, 24-40.

Moss, R. H., Edmonds, J.A., Hibbard, K. A., Manning, M. R., Rose, S. K., van Vuuren, D. P., Carter, T. R., Emori, S., Kainuma, M., Kram, T., Meehl, G. a:, Mitchell, J. F. B., Nakicenovic, N., Riahi, K., Smith, S. J., Stouffer, R. J., Thomson, A. M., Weaynt J. P., Wilbanks, T. J. (2010). The next generation of scenarios for climate change research and assessment. Nature, Vol 463, doi:10.1038/nature08823.

Robertson L., Langner, J., Engardt, M. (1999). An Eulerian limited-area atmospheric transport model, $J$. Appl. Meteorol., 38.

Roeckner, E., Brokopf, R., Esch, M., Giorgetta, M., Hagemann, S. and co-authors. (2006). Sensitivity of simulated climated to horizontal and vertical resolution in the ECHAM5 atmosphere model. J. Clim., 19. 